\title{
Listeria monocytogenes: Informe de un aumento de casos en mujeres embarazadas y revisión de la literatura
}

\author{
L. Miguel Noriega R., Sebastián Ibáñez V., Patricia González A., Masami Yamamoto C., Julio Astudillo D., \\ Marcelo González V., Rodrigo Riveros K., Fernando Lira C., Alejandra Marcotti S., Jorge Pérez G., \\ Luis Thompson M., Ma Francisca Daza P., Maximiliano Espinosa I., Constanza Pinochet V. y Pablo A. Vial C.
}

Clínica Alemana, Santiago, Chile Departamento Medicina, Unidad Infectología (LMNR, AMS, JPG, LTM) Departamento de Laboratorio (PGA, PAVC) Departamento Ginecología y Obstetricia (MYC, JAD, MGV, RRK, FLC) Departamento de Pediatría (PAVC)

Facultad de Medicina Clínica

Alemana/Universidad del Desarrollo (LMNR, SIV, PGA, MYC, JAD, MGV, RRK, FLC, AMS, JPG, LTM, MFDP, MEI, CPV, PAVC) Hospital Padre Hurtado (MYC, JPG)

Becado de la Especialidad de Medicina Interna (SIV)

Alumnos de Medicina (MFDP, MEI,

Recibido: 22 de agosto 2008 Aceptado: 29 de agosto 2008

Correspondencia a: L. Miguel Noriega Ricalde Inoriega@alemana.cl

\section{Listeria monocytogenes: Report of a rise in pregnant women and literature review}

Listeria monocytogenes, rare pathogen in the general population, causes serious infections in patients at the extreme ages of life, pregnant woman, and those with immunosuppression. The clinical manifestations are essential to suspect the disease in patients at risk, allowing an early prescription of antimicrobial therapy, before the results of the cultures are available. Clinical course and prognosis depends on how early treatment is started and, in pregnant women, the gestational age. In Clínica Alemana, at Santiago, we detected a 15 fold rate rise of neonatal listeriosis between year 2007 and 2008. Ten cases were diagnosed between January and July 2008 and the seven cases occurring in pregnant women are reported here. All these patients were in their first pregnancy, which could be associated with similar lifestyle and food habits. Considering this new epidemiological scenario, it is important to educate the population, and to conduct an epidemiological study in order to determine the national situation of Listeria monocytogenes infection.

Key words: Listeriosis, pregnancy, neonatal sepsis.

Palabras clave: Listeriosis, embarazo, sepsis neonatal.

\section{Introducción}

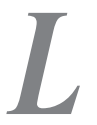

isteria monocytogenes es un bacilo grampositivo ampliamente distribuido en la naturaleza que, ocasionalmente, causa enfermedad en humanos, tanto en forma esporádica como en brotes, afectando principalmente a mujeres embarazadas y pacientes inmunodeprimidos.

Puede ser cultivada de muestras de tierra, vegetales y agua, en múltiples animales, aves e insectos y en la microbiota intestinal de 1 a $10 \%$ de los individuos $\operatorname{sanos}^{1,2}$. Además de su extensa distribución en el ambiente, crece en un amplio rango de temperaturas (de $7{ }^{\circ} \mathrm{C}$ a $45^{\circ} \mathrm{C}$ ). La contaminación de alimentos con $L$. monocytogenes es común y existe evidencia de que una alta proporción de los casos de enfermedad en humanos son adquiridos por ingestión de alimentos contaminados $^{1-3}$. También puede ser adquirida por otras vías, especialmente en el contexto ocupacional, por veterinarios y personas en contacto cercano con animales ${ }^{4,5}$.

En personas inmunocompetentes, la ingestión de alimentos con una alta dosis de bacterias puede asociarse a una gastroenteritis febril ${ }^{2}$. Se habla de listeriosis o infección invasora, cuando la bacteria se aísla en sangre, líquido cefalorraquídeo (LCR) u otro sitio esté- ril. En pacientes inmunocomprometidos, las formas clínicas más frecuentes son meningitis y sepsis.

Durante el embarazo se presenta con fiebre, mialgias, lumbalgia, malestar general y ocasionalmente diarrea, vómitos y dolor abdominal. La enfermedad tiene una fase bacteriémica en la cual se puede diseminar vía transplacentaria y producir una infección fetal intrauterina, corioamnionitis, parto prematuro, muerte fetal in utero o sepsis neonatal precoz ${ }^{6-8}$.

En Clínica Alemana de Santiago se registran entre uno y tres casos de listeriosis al año, principalmente en pacientes inmunodeprimidos por enfermedades oncológicas. Sin embargo, durante los primeros siete meses del año 2008, hemos observado un aumento significativo en el número de casos, mayoritariamente en mujeres embarazadas. El objetivo de este artículo es destacar este inusual aumento de casos y establecer una alerta que permita determinar las características epidemiológicas de la infección en Chile, identificar factores de riesgo y estimular la sospecha clínica, documentación microbiológica y notificación de los casos.

\section{Casos clínicos}

Entre enero y julio del 2008 se han diagnosticado 10 casos de infección por L. monocytogenes, siete de los 
cuales se ocurrieron en mujeres embarazadas y tres en pacientes inmunodeprimidos. A continuación informamos las características de la presentación clínica, diagnóstico, tratamiento y evolución de los casos obstétricos (Tabla 1).

Caso 1. Paciente de 31 años, FO (fórmula obstétrica: gestación, abortos, partos): G1A1P0, cursando embarazo fisiológico de 18 semanas. Consultó por cuadro de cinco días de evolución, con malestar general, cefalea y fiebre hasta $39,5^{\circ} \mathrm{C}$, acompañada de escalofríos. El examen físico era normal y no presentaba dinámica uterina. En los exámenes de ingreso, destacaba hemograma con 8.700 leucocitos $/ \mathrm{mm}^{3}, 9 \%$ baciliformes, VHS $46 \mathrm{~mm} / \mathrm{h}$ y PCR $5,3 \mathrm{mg} / \mathrm{dl}$. Hemocultivos se informaron positivos a L. monocytogenes serotipo 4. Se trató con ampicilina y gentamicina endovenosa durante 21 días, con buena evolución clínica, llegando su embarazo a término con $\mathrm{RN}$ vivo y sano.

Caso 2. Paciente de 25 años, FO: G1A0P0, sana, cursando embarazo gemelar de 22 semanas. Consultó por cuatro días de cefalea intensa y lumbalgia, a lo que se le agregó las últimas 24 horas fiebre hasta $38^{\circ} \mathrm{C}$ y escalofríos. Se realizó estudio de LCR que resultó normal. Hemograma con 17.000 leucocitos $/ \mathrm{mm}^{3}$ y $9 \%$ baciliformes. VHS $39 \mathrm{~mm} / \mathrm{h}$ y PCR 3,5 mg/dl. Los cultivos de sangre y secreción vaginal fueron positivos a L. monocytogenes serotipo 4 . Se trató con penicilina y gentamicina. Evolucionó con dinámica uterina, pérdi-

\begin{tabular}{|c|c|c|c|c|c|c|c|c|c|c|}
\hline Paciente & Edad & F. 0. & Diagnóstico & $\begin{array}{l}\text { Labor } \\
\text { ing }\end{array}$ & $\begin{array}{l}\text { ratorio } \\
\text { yreso }\end{array}$ & Presentación & Tipo cultivo & Serotipo & $\begin{array}{l}\text { Terapia } \\
\text { materna }\end{array}$ & Evolución \\
\hline 1 & 31 años & G2A1P0 & $\begin{array}{l}\text { Embarazo } \\
18 \text { semanas }\end{array}$ & $\begin{array}{l}\mathrm{L} \\
\mathrm{BaC} \\
\mathrm{VHS} \\
\mathrm{PCR}\end{array}$ & $\begin{array}{r}8.700 \\
9 \% \\
46 \\
5,3\end{array}$ & $\begin{array}{l}5 \text { días de fiebre, } \\
\text { calofríos, cefalea } \\
\text { y mialgias leves }\end{array}$ & $\begin{array}{l}\text { Hemocultivos }+ \\
19,2 \text { hrs* }^{*}\end{array}$ & 4 & $\begin{array}{l}\text { Ampicilina y } \\
\text { gentamicina }\end{array}$ & $\begin{array}{l}\text { Madre con buena evolución, } \\
\text { embarazo a termino y RN } \\
\text { sano sin tratamiento }\end{array}$ \\
\hline 2 & 25 años & GOAOPO & $\begin{array}{l}\text { Embarazo } \\
\text { gemelar } \\
22 \text { semanas }\end{array}$ & $\begin{array}{l}\mathrm{L} \\
\mathrm{BaC} \\
\mathrm{VHS} \\
\mathrm{PCR}\end{array}$ & $\begin{array}{r}7.000 \\
9 \% \\
39 \\
3,5\end{array}$ & $\begin{array}{l}4 \text { días de cefalea } \\
\text { intensa y dolor } \\
\text { lumbar y } 2 \text { días } \\
\text { de fiebre }\end{array}$ & $\begin{array}{l}\text { Hemocultivo }+ \\
20 \text { hrs. } \\
\text { Cultivo vaginal } \\
\text { al ingreso + }\end{array}$ & 4 & $\begin{array}{l}\text { Penicilina y } \\
\text { gentamicina }\end{array}$ & $\begin{array}{l}\text { Cesárea a las } 25 \text { semanas, } \\
\text { Prematuros con sepsis } \\
\text { neonatal. Madre y RN con } \\
\text { buena evolución }\end{array}$ \\
\hline 3 & 29 años & G1A0P0 & $\begin{array}{l}\text { Embarazo } \\
30 \text { semanas }\end{array}$ & $\begin{array}{l}\mathrm{L} \\
\mathrm{BaC} \\
\mathrm{VHS} \\
\mathrm{PCR}\end{array}$ & $\begin{array}{r}5.400 \\
20 \% \\
5 \\
14,7\end{array}$ & $\begin{array}{l}\text { Dolor lumbar y } \\
\text { síntomas de } \\
\text { parto prematuro } \\
24 \text { hrs de evolu- } \\
\text { ción. Sin fiebre. } \\
\text { LA sugerente } \\
\text { de infección }\end{array}$ & $\begin{array}{l}\text { Hemocultivo + } \\
\text { RN } 21 \text { hrs } \\
\text { Cultivo LA + }\end{array}$ & 4 & Penicilina & $\begin{array}{l}\text { Cesárea a las } 12 \text { hrs de } \\
\text { ingreso Madre y RN con } \\
\text { buena evolución }\end{array}$ \\
\hline 4 & 30 años & G1A0P0 & $\begin{array}{l}\text { Embarazo } \\
28 \text { semanas }\end{array}$ & $\begin{array}{l}\mathrm{L} \quad 2 \\
\mathrm{BaC} \\
\mathrm{VHS} \\
\mathrm{PCR}\end{array}$ & $\begin{array}{r}2.000 \\
8 \% \\
39 \\
6,76\end{array}$ & $\begin{array}{l}\text { Fiebre de } 24 \text { hrs } \\
\text { Síntomas parto } \\
\text { prematuro } \\
\text { Contractura } \\
\text { uterina }\end{array}$ & $\begin{array}{l}\text { Hemocultivo }+ \\
23,5 \text { hrs }\end{array}$ & 4 & Penicilina & $\begin{array}{l}\text { Cesárea por óbito fetal } \\
\text { Buena evolución la madre }\end{array}$ \\
\hline 5 & 35 años & G1A0P0 & $\begin{array}{l}\text { Embarazo } \\
12,5 \text { semanas }\end{array}$ & $\begin{array}{l}\mathrm{L} \\
\mathrm{BaC} \\
\mathrm{VHS} \\
\mathrm{PCR}\end{array}$ & $\begin{array}{r}7.600 \\
38 \% \\
34 \\
7,9\end{array}$ & $\begin{array}{l}3 \text { días de fiebre, } \\
\text { calofríos. Escasa } \\
\text { hemorragia } \\
\text { genital }\end{array}$ & $\begin{array}{l}\text { Hemocultivo }+ \\
25,1 \text { hrs }\end{array}$ & 4 & $\begin{array}{l}\text { Penicilina y } \\
\text { gentamicina }\end{array}$ & $\begin{array}{l}\text { Legrado por aborto retenido } \\
\text { Madre con buena evolución }\end{array}$ \\
\hline 6 & 30 años & G1A0P0 & $\begin{array}{l}\text { Embarazo } \\
37 \text { semanas }\end{array}$ & $\begin{array}{l}\mathrm{L} \\
\mathrm{BaC} \\
\text { VHS } \\
\text { PCR }\end{array}$ & $\begin{array}{r}6.200 \\
26 \% \\
46 \\
9,0\end{array}$ & $\begin{array}{l}1 \text { semana de } \\
\text { malestar general } \\
4 \text { días de fiebre } \\
\text { y calofríos }\end{array}$ & $\begin{array}{l}\text { Hemocultivo }+ \\
18,6 \text { hrs }\end{array}$ & 4 & $\begin{array}{l}\text { Penicilina y } \\
\text { gentamicina }\end{array}$ & $\begin{array}{l}\text { Cesárea a las } 12 \text { horas de } \\
\text { ingreso } \\
\text { Madre y RN con buena } \\
\text { evolución }\end{array}$ \\
\hline 7 & 29 años & G1A0P0 & $\begin{array}{l}\text { Embarazo } \\
34 \text { semanas }\end{array}$ & $\begin{array}{l}\mathrm{L} \\
\mathrm{BaC} \\
\mathrm{VHS} \\
\mathrm{PCR}\end{array}$ & $\begin{array}{r}2.500 \\
5 \% \\
61 \\
3,3\end{array}$ & $\begin{array}{l}2 \text { días de males- } \\
\text { tar general, } \\
\text { fiebre y bajos } \\
\text { movimientos } \\
\text { fetales }\end{array}$ & $\begin{array}{l}\text { Hemocultivos } \\
\text { RN }+19,5 \mathrm{hrs} \\
\text { Cultivo LA + } \\
\text { Madre sin } \\
\text { hemocultivo }\end{array}$ & 4 & $\begin{array}{l}\text { Penicilina y } \\
\text { gentamicina }\end{array}$ & $\begin{array}{l}\text { Cesárea a las } 6 \text { horas de } \\
\text { ingreso } \\
\text { Madre y RN con buena } \\
\text { evolución }\end{array}$ \\
\hline
\end{tabular}


da de líquido amniótico (LA) y sangre por la vagina. Requirió tocolisis y finalmente cesárea a las 25 semanas. Los dos RN (550 y 600 gramos, respectivamente) evolucionaron con signos de sepsis neonatal precoz, controlándose con apoyo intensivo y antibacterianos. Tanto la madre como los dos RN egresaron en buenas condiciones.

Caso 3. Paciente de 29 años, FO: G1A0P0, sana, cursando embarazo físiológico de 30 semanas. Consultó por síntomas de parto prematuro y lumbalgia importante, con 24 horas de evolución. No relataba fiebre ni escalofríos. Se realizó amniocentesis que mostraba elementos sugerentes de infección ovular, por lo que se inició terapia con penicilina y gentamicina y se procedió a realizar cesárea. El hemograma mostraba 15.400 leucocitos $/ \mathrm{mm}^{3}$ y $20 \%$ baciliformes. VHS $75 \mathrm{~mm} /$ h y PCR $14,7 \mathrm{mg} / \mathrm{dl}$. Los hemocultivos del RN y el cultivo de la amniocentesis fueron positivos a $L$. monocytogenes serotipo 4. La madre y el RN evolucionaron sin problemas.

Caso 4. Paciente de 30 años, FO: G1A0P0, sana, cursando embarazo fisiológico de 28 semanas. Consultó por fiebre de 24 horas de evolución, sin escalofríos e intensa dinámica uterina. Se realizó una amniocentesis sin elementos sugerentes de infección ovular. El hemograma mostraba 22.800 leucocitos $/ \mathrm{mm}^{3}$ y $8 \%$ baciliformes. VHS $39 \mathrm{~mm} / \mathrm{h}$ y PCR $6,7 \mathrm{mg} / \mathrm{dl}$. A las cuatro horas del ingreso presentó contractura uterina con óbito fetal. Los cultivos de sangre y LA fueron positivos a L. monocytogenes serotipo 4. La madre recibió tratamiento con penicilina y evolucionó en buenas condiciones.

Caso 5. Paciente de 35 años, con antecedentes de hipotiroidismo en terapia sustitutiva. FO: G1A0P0. Cursando embarazo de 12,5 semanas, consultó por fiebre y escalofríos, con tres días de evolución y hemorragia vaginal escasa. No presentaba dinámica uterina. Hemograma con 7.600 leucocitos $/ \mathrm{mm}^{3}$, 38\% baciliformes, VHS $34 \mathrm{~mm} / \mathrm{h}$ y PCR 7,9 mg/dl. Los hemocultivos fueron positivos a $L$. monocytogenes serotipo 4. A las 72 horas de terapia antimicrobiana con penicilina y gentamicina, persistía con fiebre hasta $38,5^{\circ} \mathrm{C}$ y escalofríos. Se constató la ausencia de latidos cardio-fetales y se procedió a efectuar un legrado. La madre evolucionó sin complicaciones y completó 14 días de tratamiento con amoxicilina oral.

Caso 6. Paciente de 30 años, FO: G1A0P0. Cursando embarazo fisiológico de 37 semanas. Una semana antes de ser internada presentó diarrea autolimitada durante 24 horas, seguida de malestar general hasta cuatro días previo el ingreso, en que presentó fiebre hasta $38{ }^{\circ} \mathrm{C}$ y escalofríos en una oportunidad. Hemograma con 6.200 leucocitos $/ \mathrm{mm}^{3}$, baciliformes $26 \%$, VHS 46 mm/h y PCR $9 \mathrm{mg} / \mathrm{dl}$. El estudio de LA fue negativo y los hemocultivos fueron positivos a $L$. monocytogenes serotipo 4. Se inició terapia con penicilina y gentamicina y se resolvió el parto mediante cesárea a las 24 horas del ingreso. La evolución clínica materna y del $\mathrm{RN}$ fue favorable.

Caso 7. Paciente de 29 años, FO: G1A0P0, cursando embarazo fisiológico de 34 semanas. Consultó por decaimiento, sensación febril no cuantificada y disminución de los movimientos fetales las últimas 48 horas. Se constató viabilidad fetal pero con poca movilidad. Hemograma con 22.500 leucocitos $/ \mathrm{mm}^{3}$, 5\% baciliformes, VHS $61 \mathrm{~mm} / \mathrm{h}$ y PCR $3,3 \mathrm{mg} / \mathrm{dl}$. Se inició antibioterapia con penicilina y gentamicina y se procedió a realizar una cesárea, con $\mathrm{RN}$ de aspecto sano a pesar de LA con meconio. Los cultivos de LA y sangre del RN fueron positivos a L. monocytogenes serotipo 4. La evolución clínica materna y del RN estuvo libre de complicaciones.

En resumen, se trata de siete mujeres embarazadas, una en primer trimestre, dos en segundo trimestre y cuatro en tercer trimestre de gestación, que presentaron un cuadro febril, aislándose L. monocytogenes en hemocultivos y/o LA. Sólo uno (14\%) de los embarazos llegó a término luego de recibir el tratamiento antimicrobiano correspondiente y dio a luz un RN normal sin evidencias de infección; en dos (28\%) casos se produjo muerte fetal a las 12 y 28 semanas de gestación y las cuatro mujeres restantes presentaron síntomas de parto prematuro decidiéndose efectuar una cesárea a las pocas horas del ingreso, con cuatro $\mathrm{RN}$ (incluidos gemelos) con signos de sepsis neonatal que recibieron antibioterapia y evolucionaron satisfactoriamente y un RN que nació sin signos de infección, que recibió tratamiento antimicrobiano por el antecedente materno y evolucionó sin compromiso clínico.

\section{Discusión}

El alto número de casos de listeriosis detectado en nuestro centro, sin duda representa un cambio en el comportamiento epidemiológico de esta infección, que debe ser investigado. Entre los casos no se han establecido vínculos epidemiológicos específicos que sugirieran una fuente común, y es posible que este brote sea una señal de aumento en exposición a alimentos contaminados con L. monocytogenes, derivado de cambios de hábitos de alimentación en la población, o de 
factores asociados a la preparación o conservación de alimentos. La mayoría de los casos de listeriosis en humanos son atribuidos a ingesta de alimentos contaminados y sólo ocasionalmente la listeriosis se transmite como una zoonosis. La infección en mujeres embarazadas se asocia a transmisión vertical, que representa la única circunstancia de transmisión persona a persona documentada.

El primer brote de enfermedad invasora atribuido a los alimentos fue publicado en $1983^{4}$; desde esa fecha, se han notificado numerosos brotes de esta infección en Norteamérica y Europa, confirmando la importancia de los alimentos en su transmisión ${ }^{5}$.

Listeria monocytogenes es un coco-bacilo grampositivo corto, anaerobio facultativo, que crece en agar sangre y produce una $\beta$-hemólisis incompleta. Es capaz de crecer en un amplio rango de temperatura $\left(-7^{\circ}\right.$ a $45^{\circ} \mathrm{C}$ ), que incluye los rangos de refrigeración habitual de alimentos, niveles de $\mathrm{pH}$ entre 4,4 y 9,4 y altas concentraciones de sal, lo que le permite sobrevivir por más tiempo en condiciones ambientales adversas ${ }^{6}$. Ampliamente distribuido en el ambiente, se ha aislado en tierra, vegetación, forraje, materia fecal y aguas servidas. Se encuentra en lugares donde se procesa alimento, particularmente si éste es frío y húmedo. Está frecuentemente presente en comidas crudas de origen animal o vegetal y en productos cocinados, por contaminación posterior a la cocción ${ }^{1}$. Estas características de ubicuidad y resistencia al ambiente dificultan su eliminación, obligando a estrictas medidas de control en el procesamiento de alimentos.

Hay 17 serotipos de L. monocytogenes identificados. Más de $95 \%$ de las infecciones en humanos se producen por los serotipos $1 / 2 \mathrm{a}, 1 / 2 \mathrm{~b}$ y $4 \mathrm{~b}$. Este último es el causante de la mayoría de los brotes atribuibles a alimentos contaminados y es el que produce la mayor mortalidad $^{7}$. Nuestros casos en mujeres gestantes fueron todos serotipo 4 lo que, considerando la unidad geográfica de los pacientes, pertenecientes todos a comunas del sector oriente de la capital (sector socioeconómico alto), obliga a descartar una fuente común. En todos ellos, se consignó el consumo de alimentos susceptibles de contaminación, pero aún no se ha realizado un análisis epidemiológico que permita evaluar los posibles factores de riesgo o alimentos implicados.

Listeria monocytogenes es un patógeno intracelular que ingresa al organismo por vía oral. El inoculo requerido para producir infección es desconocido y la reducción de la acidez gástrica aumenta la susceptibilidad. El período de incubación es variable, oscilando entre 11 y 70 días $^{9}$. La bacteria cruza la pared intestinal induciendo su endocitosis en células epiteliales, mediada por proteínas de superficie (internalinas) que interactúan con receptores de las células epiteliales. Traspasada la barrera intestinal, llega a las células de Kupffer en el hígado, crece en el citoplasma y se mueve, de célula en célula, infectando los hepatocitos.

Hay dos proteínas que juegan un rol fundamental en su patogenia; una es la listeriolisina $O$, responsable de la ruptura de la membrana fagosomal y de permitir la multiplicación intracelular de la bacteria y la otra, la proteina Act A, que media el ensamblaje de filamentos de actina y propulsión de la bacteria intra e intercelularmente. Este movimiento del organismo, sin exponerse al medio extracelular, le permite eludir la acción de anticuerpos, neutrófilos y complemento ${ }^{1,10}$.

La resistencia a infección, es principalmente mediada por la inmunidad celular. Las células $\mathrm{T}$ citotóxicas $(\mathrm{CD} 8+)$ reconocen y lisan células infectadas y las bacterias extracelulares son atacadas por fagocitos activados circulantes ${ }^{11}$. En pacientes con disminución de la inmunidad celular no se logra controlar la multiplicación y se produce bacteriemia e invasión de órganos, especialmente, cerebro y útero grávido. No se conocen con claridad los mecanismos que favorecen el tropismo a la placenta y las meninges, pero pudieran estar relacionados con la proteína internalina ${ }^{12}$.

La listeriosis es una enfermedad relativamente infrecuente. La incidencia anual reportada varía de 0,1 a 11,3 casos por millón de personas ${ }^{13}$. La incidencia en E.U.A. en el año 2007 fue de 0,27 por 100.000 personas, con un descenso significativo de la incidencia desde principio de los 90, relacionado con la aplicación de programas para evitar la comercialización de alimentos $\operatorname{contaminados}^{14}$. Esta reducción también se vio inicialmente en Europa; sin embargo, a partir del año 2000 se ha notificado un aumento de casos, llegando algunos países a duplicar la incidencia en seis años. Este aumento está constituido principalmente por pacientes inmunodeprimidos hematológicos, mientras en los casos en mujeres embarazadas continúa una tendencia a la disminución. Las diferentes normas exigidas en E.U.A. y Europa para alimentos preparados pueden explicar esta diferencia ${ }^{15,16}$.

En nuestro medio, la infección por L. monocytogenes no es una infección de notificación obligatoria. La información disponible respecto a frecuencia, año y tipo de infección proviene de las muestras enviadas al Instituto de Salud Pública (ISP) para su confirmación ${ }^{17}$. En los años 2006, 2007 y hasta mayo del 2008, el total de cepas enviadas al ISP fue 50, 44 y 43, respectivamente $^{18}$. De estos casos, se señala que 21,7 y 21 cepas en cada año correspondieron a hemocultivos, la mayoría de adultos, aunque no en todos los casos se consignó la edad. Aproximadamente un tercio de las cepas informadas correspondían a mujeres embarazadas o RNs (Tabla 2). 


\begin{tabular}{|c|c|c|c|}
\hline & Año 2006 & Año 2007 & al 2 junio 2008 \\
\hline Hemocultivos adultos & 12 & 4 & 13 \\
\hline Hemocultivos $\sin$ edad & 9 & 3 & 8 \\
\hline Liquido cefalorraquídeo & 8 & 14 & 8 \\
\hline Mujeres embarazadas & 3 & 1 & 5 \\
\hline Recién nacidos & 14 & 16 & 8 \\
\hline Alimentos & 4 & 5 & 0 \\
\hline Liquido ascítico & 0 & 1 & 0 \\
\hline Liquido pericárdico & 0 & 0 & 1 \\
\hline Total & 50 & 44 & 43 \\
\hline
\end{tabular}

En nuestro centro, la tasa de incidencia en mujeres gestantes el año 2007 fue de 0,28/1.000 embarazos y hasta julio 2008 es de 4,20/1000, es decir un aumento de 15 veces. La mayoría de los reportes en Chile son de casos neonatales ${ }^{19-24}$, salvo por un caso reportado en una mujer embarazada de 16 semanas $^{25}$, una bacteriemia en un paciente cirrótico ${ }^{26}$ y tres casos de posible rombo-encefalitis por listeria ${ }^{27}$.

Entre los años 1990 y 1997 se estudió la prevalencia de L. monocytogenes en varios alimentos de consumo común en Santiago. Se tomaron muestras de helados (n: $603 ; 3,5 \%$ positivas), quesos blandos (n: $256 ; 0,8 \%$ positivas), quesos duros (n: 155; todas negativas), biberones (n: 229, todas negativas), cecinas (n: 634, considerando embutidos, patés y jamones; $3,6 \%$ positivas), y mariscos (n: $268 ; 11,6 \%$ positivas). Del total de 2.145 muestras, 3,6\% estaban contaminadas ${ }^{28}$.

La reglamentación sanitaria chilena no incluye este patógeno entre las especificaciones de vigilancia para productos de consumo nacional. Sólo se vigila en preparados cárnicos listos para el consumo y productos lácteos de exportación. En E.U.A. en cambio, existe tolerancia cero en alimentos listos para el consumo, y la Comunidad Europea sólo acepta niveles de $<100$ UFC/g en alimentos para poblaciones no sensibles ${ }^{16}$.

Al analizar nuestros casos, llama la atención que todas las mujeres embarazadas corresponden a primigestas. Esta condición, puede asociarse a condiciones de vida en común, como vivir en hogares sólo compartidos con su pareja, con frecuente consumo de alimentos preparados, mantención de estos alimentos en refrigeradores por más tiempo que el recomendado, mayor frecuencia de alimentación en locales de comida rápida y probablemente hábitos de limpieza de refrigeradores y cocinas no óptimos. Si a esto se le agrega que las comidas preparadas para llevar han tenido un auge importante los últimos años y su precio es relati- vamente bajo, podemos configurar un patrón de riesgo para listeriosis.

Los síntomas de listeriosis no son específicos, y se confunden con otras enfermedades infecciosas, requiriéndose para un diagnóstico oportuno un alto grado de sospecha. En nuestro grupo de enfermas, las pacientes embarazadas mostraron un perfil clínico que permite pensar en listeriosis en forma precoz. La mayoría presentó fiebre acompañada de escalofríos, con compromiso del estado general importante, dinámica uterina, elevación discreta de PCR, hemograma con leucocitosis y desviación a izquierda, sin elementos de focalización. Las mialgias y lumbalgia también fueron elementos orientadores, consignado en tres pacientas como síntoma relevante al ingreso.

El diagnóstico se realiza por aislamiento del agente en líquidos estériles, como sangre, LCR, líquido articular o amniótico. La positividad de los cultivos en los casos analizados aquí fue en general precoz $(<$ de 24 horas), lo que permitió instaurar antibioterapia especifica. En general, no había uso de antimicrobianos previos, sólo dos pacientes habían alcanzado a usar una dosis, ante sospecha de infección respiratoria. Creemos que se debe reforzar la práctica de restricción de antimicrobianos y usarlos sólo ante la sospecha de infección bacteriana, una vez tomadas las muestras para diagnóstico microbiológico. Esto cobra especial importancia en grupos de riesgo como el aquí informado. En la tinción de Gram directa de las muestras, pueden verse características tintoriales variables que inducen a error. En nuestros casos, la mitad de los hemocultivos, fueron inicialmente informados como cocobacilos "Gram variables" o bacilos gramnegativos, por lo que la sospecha de L. monocytogenes debe estar presente en el análisis y ser conversado con los microbiólogos. La tinción de las colonias, una vez que han presentado desarrollo en placa, es segura y se logran ver los bacilos grampositivos característicos. No existen en la actualidad técnicas diagnósticas serológicas o moleculares de uso clínico, las que si están siendo desarrolladas en el ámbito de control de alimentos.

En las pacientes embarazadas, el cuadro clínico habitual es la bacteriemia, siendo inhabitual el compromiso del $\mathrm{SNC}^{29}$. Uno de cada cinco embarazos complicados con listeriosis resultan en aborto $\mathrm{u}$ óbito fetal ${ }^{8}$; esto se corresponde con lo observado en nuestra serie, en la que dos de los siete embarazos terminaron con muerte fetal.

Un tratamiento adecuado y precoz de la madre y posteriormente del RN, como ocurrió en cinco de nuestros casos, permiten una evolución materna y del niño sin complicaciones $^{30}$. En nuestra serie, una de las pacientes con infección en segundo trimestre de embara- 
zo, logró continuar su gestación a término después del tratamiento. En las otras cuatro se debió interrumpir el embarazo; una resultó en RN sin signos de infección; el embarazo gemelar (edad gestacional de 22 semanas), se frenó el parto hasta las 25 semanas en un intento de obtener viabilidad fetal, presentando los RNs gemelares un cuadro séptico que se resolvió con tratamiento antimicrobiano, al igual que en los otros 2 partos prematuros (edades gestacionales 30 y 37 semanas) en que se documentó infección en los RNs. A pesar del diagnóstico temprano, el tratamiento materno precoz y la interrupción del embarazo ante evidencias de infección ovular, sólo dos de cinco embarazos, resultaron en RNs sin infección evidente, cifra similar a lo informado previamente ${ }^{8}$.

No hay estudios clínicos que comparen la eficacia de agentes antimicrobianos en el tratamiento de la infección por L. monocytogenes. El microorganismo es susceptible a penicilinas, aminoglucósidos, cotrimoxazol, macrólidos y vancomicina. Las cefalosporinas y las quinolonas no son efectivas ${ }^{31}$, aunque hay un caso reportado de terapia exitosa con levofloxacina ${ }^{32}$. Meropenem ha demostrado buena actividad in vitro, lo que sumado a su excelente penetración a LCR, lo convierte en una alternativa a evaluar en casos seleccionados ${ }^{33}$. La resistencia adquirida a los antibacterianos comúnmente usados es inusual ${ }^{34}$, pero ha sido reportada en animales ${ }^{35}$.

El tratamiento de elección, basado en datos clínicos observacionales, es ampicilina, siendo bencilpenicilina $\mathrm{G}$ muy activa y probablemente de resultados similares $^{6}$. Nuestros casos fueron tratados con ampicilina y gentamicina el primero y luego, producto de la falta de ampicilina parenteral en Chile, se uso penicilina y gentamicina, esta última los primeros siete a 10 días. Muchos expertos recomiendan esta asociación con gentamicina para lograr un efecto sinérgico, dada la actividad bacteriostática de los $\beta$-lactámicos sobre $L$. monocytogenes $^{36}$. Cotrimoxazol es la mejor alternativa para pacientes alérgicos a penicilina, con la limitación de su uso durante el primer trimestre del embarazo, en que la toxicidad, por alterar el metabolismo del ácido fólico, es importante ${ }^{37}$. En ese caso, el uso de vancomicina o meropenen ( $\mathrm{si}$ es una alergia no grave a penicilina), son alternativas a considerar. Un estudio retrospectivo en 22 pacientes con compromiso del SNC sugirió que la combinación de ampicilina y cotrimoxazol puede ser más efectiva que la combinación de ampicilina y gentamicina ${ }^{38}$. La duración del tratamiento depende del cuadro: se recomienda 2 semanas para bacteriemia, 3 semanas para meningitis, 6 a 8 semanas para absceso cerebral o encefalitis, y 4 a 6 semanas para endocarditis.

Un $70 \%$ de los casos diagnosticados y tratados oportunamente se recuperan completamente, aunque las secuelas son frecuentes en casos de rombo-encefalitis o absceso cerebral ${ }^{2}$. La mortalidad reportada en pacientes hospitalizados por listeriosis invasora y deterioro de inmunidad celular importante, varía entre 20 y $30 \%$, a pesar de tratamiento antibacteriano adecuado. Así mismo, aproximadamente $20 \%$ de las infecciones por listeria en mujeres embarazadas tiene como resultado la muerte fetal. No se han reportado muertes en gastroenteritis por listeria ${ }^{5}$.

La situación epidemiológica aquí descrita, nos obliga a tomar medidas tendientes a minimizar el riesgo en personas con factores de riesgo para hacer una infección grave. La alerta generada en nuestra institución, fue rápidamente enfrentada por las autoridades regionales de salud y ya se inició un estudio para conocer mejor el problema en nuestra región.

Casi todos los casos de listeriosis se originan por el consumo de concentraciones altas del patógeno, por lo que las prácticas de elaboración y de manipulación de alimentos pueden influir en los niveles de contaminación y, por lo tanto, en el riesgo de infección. Las medidas de control que reducen la frecuencia de contaminación, si son exitosas, reducirán de forma proporcional la incidencia de la enfermedad, fenómeno ya experimentado en E.U.A. Las medidas más efectivas serían las que evitan la contaminación en el momento del consumo. La FDA y el CDC entregan recomenda-

\section{Tabla 3. Recomendaciones para prevenir infecciones por Listeria} monocytogenes*

En población general:

- Almacenar las comidas "listas para comer" a $4{ }^{\circ} \mathrm{C}$ o menos

- Usar los alimentos perecibles y "listos para comer" lo antes posible

- Cocer adecuadamente los productos derivados de vacunos, aves y peces

- Lavar prolijamente las verduras y frutas antes de consumir

- No consumir lácteos no pasteurizados

- Limpiar el refrigerador regularmente

- Mantener separados los distintos tipos de alimento en el refrigerador

- Mantener las superficies de cocina y utensilios limpios

En mujeres embarazadas, adultos mayores, inmunosuprimidos y otros grupos en riesgo:

- No comer hot dogs o carnes "deli" (definidas como rebanadas de carnes cocinadas, como jamón, roast beef, salame, pavo), a no ser que sean recalentadas hasta hervir

- No comer quesos blandos (azul, brie, estilo mexicano, camembert) o frescos a no ser que se consigne que se fabricó con leche pasteurizada

- No comer patés o salsas de carne. Los enlatados pueden consumirse

- No comer pescados ahumados refrigerados, salvo que estén en platos bien preparados con buena cocción

- No beber leche no pasteurizada ni comer alimentos que la contengan

*Ref 39 
ciones a los consumidores para reducir el riesgo de infección, las que se señalan, con modificaciones, en la Tabla 3.

\section{Resumen}

Listeria monocytogenes, es un patógeno poco frecuente en la población general, causante de infecciones graves en pacientes en edades extremas de la vida, mujeres embarazadas e inmunodeprimidos. La sospecha de la enfermedad en pacientes de riesgo se basa principalmente en el cuadro clínico, lo que permite iniciar un tratamiento empírico antes de contar con los resultados de los cultivos. La evolución y pronóstico dependen de la precocidad con que se inicia la terapia y de la edad gestacional. En Clínica Alemana de Santiago detectamos un aumento de 15 veces en la tasa de listeriosis comparando el año 2007 con el 2008. Entre enero y julio 2008, se diagnosticaron 10 casos, de los cuales siete fueron en primigestas, lo que podría tener relación con un hábito alimentario y características de vida similar. Es fundamental, a la vista de esta nueva realidad epidemiológica, educar a la población en hábitos alimentarios y de higiene, como también realizar un estudio epidemiológico que determine la situación nacional de infección por L. monocytogenes.

\section{Referencias}

1.- Ramaswamy V, Cresence V M, Rejitha J S, Lekshmi M U, Dharsana K S, Prasad S P, et al. Listeria-review of epidemiology and pathogenesis. J Microbiol Immunol Infect 2007; 40: 4-13.

2.- Lorber B. Listeria monocytogenes. Mandell G L, Bennett J E, Dolin R. Principles and Practice of Infectious Diseases, sexta edición. Philadelphia. Churchill Livingstone. 2005; p. 2478-

3.- McLauchlin J, Low J C. Primary cutaneous listeriosis in adults: an occupational disease of veterinarians and farmers. Vet Rec 1994; 135: $615-7$.

4.- Schlech W F 3rd, Lavigne P M, Bortolussi R A, Allen A C, Haldane E V, Wort A J, et al. Epidemic listeriosis - evidence for transmission by food. N Engl J Med 1983; 308: 203-6.

5.- Swaminathan B, Gerner-Smidt P. Epidemiology of human listeriosis. Microbes Infect 2007; 9: 1236-43.

6.- Lorber B. Listeriosis. Clin Infect Dis 1997; 24: $1-9$.

7.- Gerner-Smidt P, Ethelberg S, Schiellerup P, Christensen JJ, Engberg J, Fussing V, et al. Invasive listeriosis in Denmark 1994-2003: a review of 299 cases with special emphasis on risk factors for mortality. Clin Microbiol Infect 2005; 11: 618-24.

8.- Mylonakis E, Paliou M, Hohmann E L, Calderwood S B, Wing E J. Listeriosis during pregnancy: a case series and review of 222 cases. Medicine (Baltimore) 2002; 81: 260-9.

9.- Lindan M J, Mascola L, Lou X D, Goulet V, May S, Salminen C, et al. Epidemic listeriosis associated with Mexican-style cheese. N Engl J Med 1988; 319: 823-8.

10.- Southwick F S, Purich D L. Intracellular pathogenesis of listeriosis. N Engl J Med 1996; 334: 770-6.
11.- Parham P, Unanue E R. Immunity to $L$. monocytogenes: A model intracellular pathogen. Immunol Rev 1997; 158: 1-169.

12.- Lecuit M. Understanding how Listeria monocytogenes targets and crosses host barriers. Clin Microbiol Infect 2005; 11: 430-6.

13.- Anónimo. Risk assessment of Listeria monocytogenes in ready-to-eat foods: technical report. Microbiological Risk Assessment Series, No. 5. WHO, Rome, 2004. http://www.who.int/foodsafety/ publications/micro/mra_listeria/en/ index.html (accedido 15/08/2008).

14.- Preliminary FoodNet Data on the incidence of infection with pathogens transmitted commonly through food - 10 States, 2007. http://www.cdc.gov/mmwr/preview/ mmwrhtml/mm5714a2.htm\# (15/08/2008)

15.- Goulet V, Hedberg C, Le Monnier A, de Valk H. Increasing incidence of listeriosis in France and other European countries. Emerg Infect Dis 2008; 14: 734-40.

16.- Ministerio de Agricultura. Servicio Agrícola y Ganadero. Instructivo para el muestreo de Listeria monocytogenes en preparados cárnicos listos para el consumo y productos lácteos de exportación. Chile. 2006. http:// www.sag.gob.cl/pls/portal/docs/page/ pg_sag_biblioteca/bibl_exportaciones/ biblio_exp_pec/biblio_exp_pec_manuales/ instructivo_listeria_carnicos_lacteos.pdf (15/08/2008).

17.- Vigilancia de laboratorio de Listeria monocytogenes. ISP. http://200.68.11.21/ ivlweb/hvllismon.aspx (accedido 15/08/ 2008).

18.- MINSAL, Información Unidad de Vigilancia, Departamento Epidemiología (comunicación personal Dra. A. Olea N.), sobre confirmación de casos en Instituto de Salud Pública de Chile 2006, 2007 y hasta mayo 2008.

19.- Toro E, Quiroga M, Suárez H. Meningitis purulenta en el niño. Análisis clínico. Rev
Chil Pediatr 1975; 46: 487-93.

20.- García H, Pinto M, Ross L, Saavedra G. Brote epidémico de listeriosis neonatal. Rev Chil Pediatr 1981; 54: 330-5.

21.- Barraza P, Topelberg S, Lagos R. Meningitis bacteriana: resultados clínicos. Rev Chil Pediatr 1993; 64: 22-5.

22.- Oto M, Samamé M, Camponovo R, Pinto $\mathrm{M}$, Arredondo O, Henríquez M, et al. Infecciones bacterianas neonatales. Rev Chil Pediatr 1994; 65: 107-13.

23.- Ovalle A, Kakariela E, Correa A, Vial M, Aspillaga C. Estudio anatómo-clínico de las causas de muerte fetal. Rev Chil Obstet Ginecol 2005; 70: 303-12.

24.- Tapia J L, Reichhard C, Saldías I, Abarzúa F, Pérez M E, González A, et al. Sepsis neonatal en la era de profilaxis antimicrobiana prenatal. Rev Chil Infect 2007; 24: 111-16.

25.- Cisternas A, Lagos N, Galstuch J, González C, García C, Díaz J. Infección por Listeria monocytogenes y embarazo con buen resultado perinatal. Rev Chil Obstet Ginecol 2002; 67: 237-41.

26.- Chanqueo L, Gutiérrez C, Armas R, Urriola G, Bustos M, Tapia C, et al. Bacteriemia primaria por Listeria monocytogenes en paciente con cirrosis hepática. Caso clínico. Rev Méd Chile 2008; 136: 225-9.

27.- Illanes S, Araya P, Ferrer S, Cartier L, Bravo M, Castillo S. Romboencefalitis: una forma de infección por Listeria monocytogenes en el sistema nervioso central. Rev Méd Chile 2003; 131: 921-8.

28.- Cordano A M, Rocourt J. Occurrence of Listeria monocytogenes in food in Chile. Int J Food Microbiol 2001; 70: 175-8.

29.- Gellin B G, Broome C V. Listeriosis. JAMA 1989; 261: 1313- 20.

30.- Silver H M. Listeriosis during pregnancy. Obstet Gynecol Surv 1998; 53: 737-40. 
31.- Troxler R, von Graevenitz A, Funke G, Wiedemann B, Stock I. Natural antibiotic susceptibility of Listeria species: $L$. grayi, $L$. innocua, $L$. ivanovii, L. monocytogenes, $L$. seeligeri and L. welshimeri strains. Clin Microbiol Infect 2000; 6: 525-35.

32.- Viale P, Furlanut M, Cristini F, Cadeo B, Pavan F, Pea F. Major role of levofloxacin in the treatment of a case of Listeria monocytogenes meningitis. Diagn Microbiol Infect Dis 2007; 58: 137-9.

33.- Manfredi R, Sabbatani S, Marinacci G, Salizzoni E, Chiodo F. Listeria monocytogenes meningitis and multiple brain abscesses in an immunocompetent host. Favorable response to combination linezolid- meropenem treatment. J
Chemother 2006; 18: 331-3.

34.- Hansen J M, Gerner-Smidt P, Bruun B. Antibiotic susceptibility of Listeria monocytogenes in Denmark 1958-2001. APMIS 2005; 113: 31-6.

35.- Srinivasan V, Nam H M, Nguyen L T, Tamilselvam B, Murinda S E, Oliver S P. Prevalence of antimicrobial resistance genes in Listeria monocytogenes isolated from dairy farms. Foodborne Pathog Dis 2005; 2: 201-11.

36.- Mylonakis E, Hohmann E L, Calderwood S B. Central nervous system infection with Listeria monocytogenes. 33 years' experience at a general hospital and review of 776 episodes from the literature. 1998; 77: 313-6.
37.- Spitzer P G, Hammer S M, Karchmer A W. Treatment of Listeria monocytogenes infection with trimethoprimsulfamethoxazole: Case report and review of the literature. Rev Infect Dis 1986; 8: 427-30.

38.- Merle-Melet M, Dossou-Gbete L, Maurer P, Meyer P, Lozniewski A, Kuntzburger O, et al. Is amoxicillin-cotrimoxazole the most appropriate antibiotic regimen for listeria meningoencephalitis? Review of 22 cases and the literature. J Infect 1996; 33: 79-85.

39.- Rados C. Preventing listeria contamination of foods. FDA Consumer Magazine. JanuaryFebruary 2004 issue. http://www.fda.gov/ fdac/features/2004/104 bac.html (accedido $15 / 08 / 2008$ ). 